\title{
Ralstonia solanacearum em Viveiros Clonais de Eucalipto no Brasil
}

\author{
Acelino C. Alfenas ${ }^{1}$, Reginaldo G. Mafia ${ }^{1}$, Robert C. Sartório ${ }^{2}$, Daniel H.B. Binoti ${ }^{1}$, Ricardo R. Silva ${ }^{1}$, \\ Douglas Lau ${ }^{1} \&$ Cláudia A. Vanetti ${ }^{1}$
}

${ }^{1}$ Departamento de Fitopatologia, Universidade Federal de Viçosa, CEP 36570-000, Viçosa, MG, e-mail: aalfenas@ufv.br; ${ }^{2}$ Aracruz Celulose S.A., CEP 29197-000, Aracruz, ES

(Aceito para publicação em 20/09/2006)

Autor para correspondência: Acelino C. Alfenas

ALFENAS, A.C., MAFIA, R.G., SARTÓRIO, R.C., BINOTI, D.H.B., SILVA, R.R., LAU, D. \& VANETTI, C.A. Ralstonia

solanacearum em viveiros clonais de eucalipto no Brasil. Fitopatologia Brasileira 31:357-366. 2006.

\begin{abstract}
RESUMO
A incidência da murcha bacteriana, causada por Ralstonia solanacearum, em viveiros clonais de eucalipto, no período de abril a setembro de 2005, resultou no descarte de cerca de 553.991 minicepas, 6.837 .691 propágulos na fase de enraizamento e 11.266.819 mudas, nos Estados da Bahia, do Espírito Santo, do Maranhão, de Minas Gerais e do Pará, totalizando um prejuízo estimado em, no mínimo, seis milhões de reais (US\$ 2,7 milhões). Em minijardim clonal, a doença caracteriza-se por necrose foliar, escurecimento anelar ou completo do lenho, murcha e morte de minicepas. Os sintomas na parte aérea são similares à morte gradual de minicepas submetidas a podas drásticas ou com sistema radicular malformado. $\mathrm{Na}$ fase de enraizamento, miniestacas infectadas podem apresentar arroxeamento das nervuras do limbo foliar e podridão. No campo, a doença caracteriza-se por bronzeamento e necrose foliar, desfolha basal, ascendente escurecimento interno do lenho e morte da planta, geralmente a partir do quarto mês após o transplantio. Os sintomas geralmente se agravam em árvores com enovelamento de raízes e afogamento de coleto. A etiologia da doença foi confirmada por meio de testes de exsudação, microscopia de varredura, isolamento da bactéria, análises de PCR/RFLP, reação de hipersensibilidade (HR) em mudas de fumo, testes de patogenicidade em plântulas de eucalipto e tomate e re-isolamento da bactéria. Como o sistema de produção de mudas clonais de eucalipto é altamente favorável à multiplicação bacteriana e na falta de conhecimento sobre a resistência genética e de outras estratégias de controle da doença, é essencial evitar a introdução da bactéria em viveiros.

Palavras-chave adicionais: murcha bacteriana, murcha vascular, Eucalyptus spp., propagação clonal, PCR/RFLP, DNA.
\end{abstract}

\begin{abstract}
Ralstonia solanacearum on eucalyptus clonal nurseries in Brazil

The occurrence of bacterial wilt caused by Ralstonia solanacearum in eucalyptus clonal hedges in the Brazilian states of Bahia, Espírito Santo, Maranhão, Minas Gerais and Pará, from April to September, 2005 resulted in loss of 553,991 rooted cuttings, 6,837,691 cuttings at rooting stage and 11,266,819 cuttings, with a total loss estimated to be at least six million reais (US\$ $2.7 \mathrm{M}$ ). In clonal minihedges, the disease is characterized by foliar necrosis, annular or complete wood darkening, wilt and death of rooted-cuttings. Leaf symptoms are similar to those observed during the gradual death of rooted-cuttings subjected to drastic pruning or with malformed root systems. In the rooting phase, infected minicuttings can present redning of leaf blade veins and cutting rot. In the field, the disease is characterized by leaf browning and necrosis, basal leaf loss, internal wood darkening and plant death, with onset generally occurring four months after transplant. Disease severity is generally higher in trees with entangled roots and overplanting. The causal agent of the disease was confirmed through exudate tests, scanning electron microscopy, bacterial isolation, PCR/RFLP analyses, hypersensitive reactions (HR) in tobacco seedlings, pathogenicity tests in eucalyptus and tomato plantlets and reisolation of the bacteria. The production of cuttings offers a highly favorable environment for bacterial multiplication. This, combined with the lack of knowledge on genetic resistance and other disease control strategies, makes it essential to avoid introduction of this bacterium in clonal nurseries.
\end{abstract}

Additional Keywords: bacterial wilt, vascular wilt, Eucalyptus spp., clonal propagation, PCR/RFLP, DNA.

\section{INTRODUÇÃO}

Em 2005, a incidência da murcha bacteriana, causada por Ralstonia solanacearum [(Smith 1896) Yabuuchi et al. 1995], resultou em elevadas perdas em viveiros de eucalipto nos Estados da Bahia, do Espírito Santo, do Maranhão, de
Minas Gerais e do Pará. Os prejuízos foram advindos do descarte de materiais utilizados em minijardim (areia, mangueiras de gotejamento, etc), propágulos e de plantas infectadas, bem como dos gastos para a erradicação de inóculo e adaptações para evitar novas contaminações nas diferentes fases da propagação clonal. Somam-se a estes 
prejuízos as perdas advindas de alterações de manejo, substituição de genótipos e de atrasos nos cronogramas de plantio. Em minijardins clonais, a murcha bacteriana pode ser confundida com o declínio e a morte de minicepas, formadas a partir de mudas velhas ou submetidas a podas drásticas e, ou, a coletas intensivas de brotações, que conduzem à morte de raízes e, conseqüentemente, redução da absorção de água e nutrientes.

No Brasil, apesar de seu grande impacto em culturas agronômicas, especialmente em tomate e batata, a murcha bacteriana é uma enfermidade relativamente recente para a eucaliptocultura. Sua primeira ocorrência data do início da década de 1980, quando Sudo et al. (1983) relataram a enfermidade em plantios de eucalipto (Eucalyptus grandis Hill ex Maiden) e bracatinga (Mimosa scabrella Benth.) no município de Prata (Triângulo Mineiro, Minas Gerais). Subseqüentemente, a enfermidade foi observada em eucalipto na Companhia Monte Dourado, no Pará (atual Jari Celulose), em 1984 e, posteriormente, na Camargo Corrêa (Tucuruí, Pará) e na Copener (Bahia) (Robbs et al., 1988). Em 1985, Dianese \& Takatsu (1985) identificaram a biovar 1 de $R$. solanacearum a partir de culturas da bactéria originárias de plantas de eucalipto cultivadas em Monte Dourado, Pará. Outros três isolados do patógeno, originários do Pará e da Bahia, foram também identificados como biovar 1 (Robbs et al., 1988). Todas essas constatações ocorreram em plantios realizados em áreas recém-desmatadas e resultaram em até $25 \%$ de mortalidade. Em 1987, cerca de um milhão de mudas de eucalipto foram dizimadas pela doença em Monte Dourado (Robbs et al., 1988).

Além do Brasil, a doença foi registrada nas principais regiões eucaliptocultoras do mundo, como China (Wu \& Liang, 1988a), Taiwan (Wang, 1992), Indonésia (Alfenas, 1993), Austrália (Askiew \& Tevorow, 1994), Venezuela (Ciesla et al., 1996) e África do Sul (Coutinho et al., 2000). Na China, E. urophylla S.T. Blake, E. tereticornis Sm., E. camaldulensis Dehnh. e híbridos de E. grandis $x$ E. urophylla ou $E$. urophylla $x E$. grandis foram os materiais genéticos mais suscetíveis. Adicionalmente, E. grandis, E. pellita F. Muell., E. propinqua Deane \& Maiden e E. saligna Sm. são listadas como espécies suscetíveis em condições de infecção natural (Wu \& Liang, 1988b).

Diante da importância da murcha bacteriana para a eucaliptocultura e dos escassos conhecimentos sobre este patossistema, o presente trabalho objetivou descrever a sintomatologia e comprovar a etiologia da doença em viveiros clonais de eucalipto, bem como quantificar as perdas causadas pela doença em 2005.

\section{MATERIAL E MÉTODOS}

\section{Sintomatologia}

A sintomatologia foi descrita a partir de inspeções em viveiros de eucalipto e análises laboratoriais de amostras oriundas dos Estados da Bahia, do Espírito Santo, do Maranhão, de Minas Gerais e do Pará, bem como de plantios em campo com seis meses de idade em São Pedro dos Ferros, Minas Gerais.

\section{Diagnose em amostras vegetais}

No laboratório de Patologia Florestal e Genética da Interação Planta-Patógeno (UFV), realizou-se a análise de 180 minicepas com sintomas da doença e de 270 sem sintomas, de seis clones híbridos de Eucalyptus spp. e de 1.260 miniestacas e 350 mudas formadas a partir de propágulos coletados em nove minijardins clonais. Amostraram-se cinco plantas com sintomas e cinco plantas aparentemente sadias no campo. A presença da bactéria foi confirmada por meio da avaliação macroscópica e microscópica de exsudação de pus bacteriano. No primeiro caso, mergulhouse a base do caule seccionado de minicepas, miniestacas e de mudas em um tubo de ensaio com água destilada. Após 1 a 3 min, observou-se a presença de exsudação na forma de fluxo bacteriano a partir da região seccionada. $\mathrm{Na}$ avaliação microscópica, três fragmentos $\left(25 \mathrm{~mm}^{2}\right.$ de área e espessura de $1 \mathrm{~mm}$ ) de tecido, retirados da região vascular, foram depositados em uma gota d'água destilada sobre uma lâmina microscópica. Posteriormente, os fragmentos foram observados ao microscópio de luz (40 X e $100 \mathrm{X})$ e avaliados quanto à presença de exsudação contínua de pus bacteriano.

\section{Análise ultraestrutural de tecidos infectados}

Análises em microscopia eletrônica de varredura (MEV) foram realizadas a fim de evidenciar a presença de células bacterianas em minicepas e visualizar os efeitos da infecção bacteriana sobre os tecidos da planta. Fragmentos de caule retirados da região do coleto de minicepas sadias e doentes, fixados em FAA 70 (formol 40\%, $5 \mathrm{ml}$, álcool 70\%, $90 \mathrm{ml}$ e ácido acético glacial, $5 \mathrm{ml}$ ), foram seccionados no sentido transversal obtendo-se cortes de aproximadamente $2 \mathrm{~mm}$ de espessura. As amostras foram transferidas para recipientes com solução de glutaraldeído $3 \%$ em tampão cacodilato de sódio $0,05 \mathrm{M}, \mathrm{pH}$ 6,9 e deixadas em geladeira a $4{ }^{\circ} \mathrm{C}$, por $12 \mathrm{~h}$. Em seguida, efetuaram-se seis lavagens sucessivas, de 10 min cada, com a mesma solução tampão. Após a pré-fixação, o material vegetal foi fixado em solução de tetróxido de ósmio $\left(\mathrm{OsO}_{4}\right)$ a $1 \%$, no mesmo tampão de cacodilato, permanecendo em refrigerador a 4 ${ }^{\circ} \mathrm{C}$ por $4 \mathrm{~h}$. Posteriormente, repetiram-se as seis lavagens sucessivas conforme previamente descrito. Após fixação, as amostras foram submetidas a uma desidratação em série alcoólica crescente de $30,50,70,80$ e $95 \%$ por $10 \mathrm{~min}$ cada. Finalmente, as amostras foram transferidas para a concentração de $100 \%$, sendo esta solução substituída por três vezes a cada 15 min. A seguir, procedeu-se a secagem ao ponto crítico do material (Balzers CPD-030), utilizando-se $\mathrm{CO}_{2}$ líquido. Os fragmentos secos foram fixados sobre suportes metálicos, cobertos com ouro por meio de pulverização catódica (Balzers, modelo SCD50). As observações foram realizadas em microscópio eletrônico de varredura (modelo LEO, $1430 \mathrm{VP}$ ) com acelerações de $10,02 \mathrm{KV}$ e distância de trabalho de $14 \mathrm{a} 15 \mathrm{~mm}$. 


\section{Isolamento}

Segmentos de caule de minicepas com exsudação bacteriana foram parcialmente desinfestados pela lavagem com água e sabão. Posteriormente, fragmentos do caule com cerca de $1 \mathrm{~cm}$ foram depositados em gotas de água esterilizada em placa de porcelana, sob condições assépticas. Após cerca de 1-2 min em repouso, com auxílio de uma alça de platina, realizou-se a transferência de alíquotas da suspensão para meio de cultivo de Kado \& Heskett (1970). Após 48 h de incubação, colônias individualizadas com características típicas de $R$. solanacearum foram transferidas e armazenadas em água destilada esterilizada e em tubos de ensaio $(15 \mathrm{~cm}$ x $1,5 \mathrm{~cm}$ ) contendo o mesmo meio de cultivo.

\section{Patogenicidade}

As culturas puras obtidas foram testadas quanto à indução de reação de hipersensibilidade (HR) em folhas de fumo e patogenicidade em mudas de tomateiro e em plântulas de eucalipto. Como padrões de $R$. solanacearum, empregaram-se os isolados CNPH 221 (biovar 1), CNPH 174 (biovar 2) e CNPH 211 (biovar 3), obtidos da EMBRAPA Hortaliças (CNPH, Brasília, DF).

Para a reação de hipersensibilidade, os isolados foram inicialmente multiplicados em meio de Kelman (1954). Após $48 \mathrm{~h}$ de incubação, a $28^{\circ} \mathrm{C}$, no escuro, selecionaramse as colônias de aspecto liso, fluido e com o centro vermelho e as bordas brancas. As colônias selecionadas foram novamente multiplicadas em meio sólido de Kado \& Heskett (1970) por $24 \mathrm{~h}$, a $28{ }^{\circ} \mathrm{C}$, no escuro. Posteriormente, preparou-se uma suspensão bacteriana em solução de cloreto de sódio $(\mathrm{NaCl}$ $0,85 \%)$ ajustada ao espectrofotômetro para uma $\mathrm{DO}_{(\lambda=550 \mathrm{~mm})}$ igual a 0,1 . Com o auxílio de uma seringa hipodérmica de 1 $\mathrm{ml}$ de capacidade, a suspensão bacteriana foi infiltrada em folhas de fumo (Nicotiana tabacum L. 'Havana 425'). Necrose localizada na área infiltrada 24 a 48 h após a inoculação foi considerada evidência de HR positiva.

Para o teste de patogenicidade em mudas de tomateiro (Lycopersicon esculentum Mill. 'St. Clara'), o crescimento bacteriano em meio de Kelman (1954), selecionado conforme descrito anteriormente, foi tocado com agulha de seringa hipodérmica, a qual foi usada para ferir a axila foliar de tomateiros com dois pares de folhas verdadeiras. As plantas foram mantidas em câmara de crescimento, a $26^{\circ} \mathrm{C}$. Após 30 dias, realizou-se a avaliação da colonização bacteriana pelo teste de exsudação em gota d'água.

Para comprovação da patogenicidade em eucalipto, realizou-se um bioensaio adaptado de Bringel et al. (2001). Uma suspensão de células do patógeno ajustada para $\mathrm{DO}_{(\lambda=550 \mathrm{~nm})}$ igual a 0,1 foi utilizada para a microbiolização de sementes de E. grandis. Após a desinfestação superficial das sementes por imersão em álcool $70 \%$, por $30 \mathrm{~s} \mathrm{e} \mathrm{em} \mathrm{hipoclorito} \mathrm{de} \mathrm{sódio} 1$ $\%$, por $3 \mathrm{~min}$, as sementes foram lavadas com água destilada esterilizada e imersas na suspensão de inóculo por $24 \mathrm{~h}$, a $30^{\circ} \mathrm{C}$. Posteriormente, as sementes foram transferidas para tubos de ensaio contendo $10 \mathrm{ml}$ de meio ágar-água $(0,85 \%)$ e a seguir mantidas a $26{ }^{\circ} \mathrm{C}$, sob fotoperíodo de $12 \mathrm{~h}$ e intensidade luminosa de $40 \mu \mathrm{M}$ de fótons. $\mathrm{s}^{-1} \cdot \mathrm{m}^{-2}$. Como testemunha utilizaram-se sementes de eucalipto desinfestadas e não microbiolizadas com o patógeno. Após 30 dias de incubação, a morte de plântulas foi registrada.

\section{Detecção por PCR (Polymerase Chain Reaction)}

A partir de colônias bacterianas sem extração de DNA, amplificou-se um fragmento interno ao rDNA16S por PCR, utilizando os oligonucleotídeos que pareiam com seqüências específicas para o gênero Ralstonia (PS1/ 5'- AGTCGAACGGCAGCGGGGG -3' e PS2/ 5'GGGGATTTCACATCGGTCTTGCA -3') (Pastrick \& Maiss, 2000). A reação foi realizada em um volume final de 25

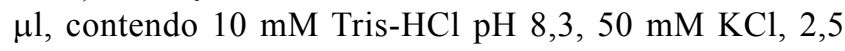
$\mathrm{mM} \mathrm{MgCl}, 0,2 \mathrm{mM}$ de cada um dos deoxinucleotídeos (dATP, dTTP, dCTP e dGTP), 0,4 $\mu \mathrm{M}$ de cada um dos oligonucleotídeos iniciadores, 1 unidade da enzima Taq DNA polimerase e água esterilizada (Milli-Q). O produto da PCR foi analisado em gel de agarose a 1,6\% em Tris Acetato EDTA (TAE), corado com brometo de etídeo $(0,5 \mu \mathrm{g} / \mathrm{ml})$ e fotodocumentado. Como controles da especificidade da reação, isolados de $R$. solanacearum pertencentes à coleção da EMBRAPA Hortaliças $(\mathrm{CNPH}$ 221 - biovar 1; CNPH 174 - biovar 2; e CNPH 211, biovar 3) e isolados de bactérias associadas ao eucalipto (patogênicas ou promotoras de crescimento) pertencentes aos gêneros Xanthomonas, Pseudomonas, Erwinia, Rhizobium e Bacillus foram utilizados nas reações. A especificidade do produto da PCR amplificado com os oligonucleotídeos PS1/PS2 foi confirmada por análise de restrição com a enzima TaqI (Pastrick \& Maiss, 2000). Alíquotas de $10 \mu \mathrm{l}$ do produto da PCR foram digeridos com $5 \mathrm{U}$ de $T a q \mathrm{I}$ a $65^{\circ} \mathrm{C}$ por $45 \mathrm{~min}$. Os produtos de restrição foram analisados por eletroforese em gel de agarose a $2 \%$ como anteriormente descrito.

\section{Quantificação das perdas causadas pela doença}

As perdas em viveiros clonais foram quantificadas quanto ao número de minicepas, propágulos vegetativos e de mudas infectadas e, conseqüentemente, destruídas para a erradicação do patógeno nos Estados da Bahia, do Espírito Santo, Maranhão, de Minas Gerais e do Pará. Os prejuízos econômicos foram estimados considerando o valor de mercado para venda de mudas equivalente a R \$350,00 (US\$ 161,30)/milheiro. Para propágulos vegetativos, ainda em fase de enraizamento, empregou-se o índice médio de $70 \%$ para conversão em mudas aptas para expedição. O valor de cada minicepa foi estimado em R $\$ 0,70$ (US\$ 0,32), considerando o preço de mercado da muda perdida e o de reposição, desconsiderando-se seu potencial produtivo, que poderia ultrapassar R $\$ 50,00$ (US\$ 23,04 ) por planta.

\section{RESULTADOS}

\section{Descrição sintomatológica da doença em viveiro}

As minicepas infectadas apresentavam uma tendência 
à murcha, porém, menos evidente se comparado com plantas infectadas pela bactéria em condições de campo. As folhas exibiam lesões grandes, irregulares escuras (Figura 1A) que se tornavam marrom claras a palha (Figura 1B). As lesões incidiam, predominantemente, próximas às bordas da folha $\mathrm{e}$, raramente, em formato de "V" invertido, considerado sintoma típico de déficit hídrico. A doença ocorreu mais severamente em minicepas com sistema radicular malformado (Figura 1C). Aparentemente, a infecção bacteriana nas raízes de integridade comprometida devido a podas drásticas (baixa qualidade do sistema radicular) acelerou o declínio (Figuras 1D e E) e a morte das minicepas (Figura 1F).

Cortes perpendiculares ao eixo principal e na região do coleto de minicepas evidenciaram alteração da coloração normal dos tecidos, que se tornavam mais escuros, geralmente em formato de anel (Figura 1G), no sentido perpendicular
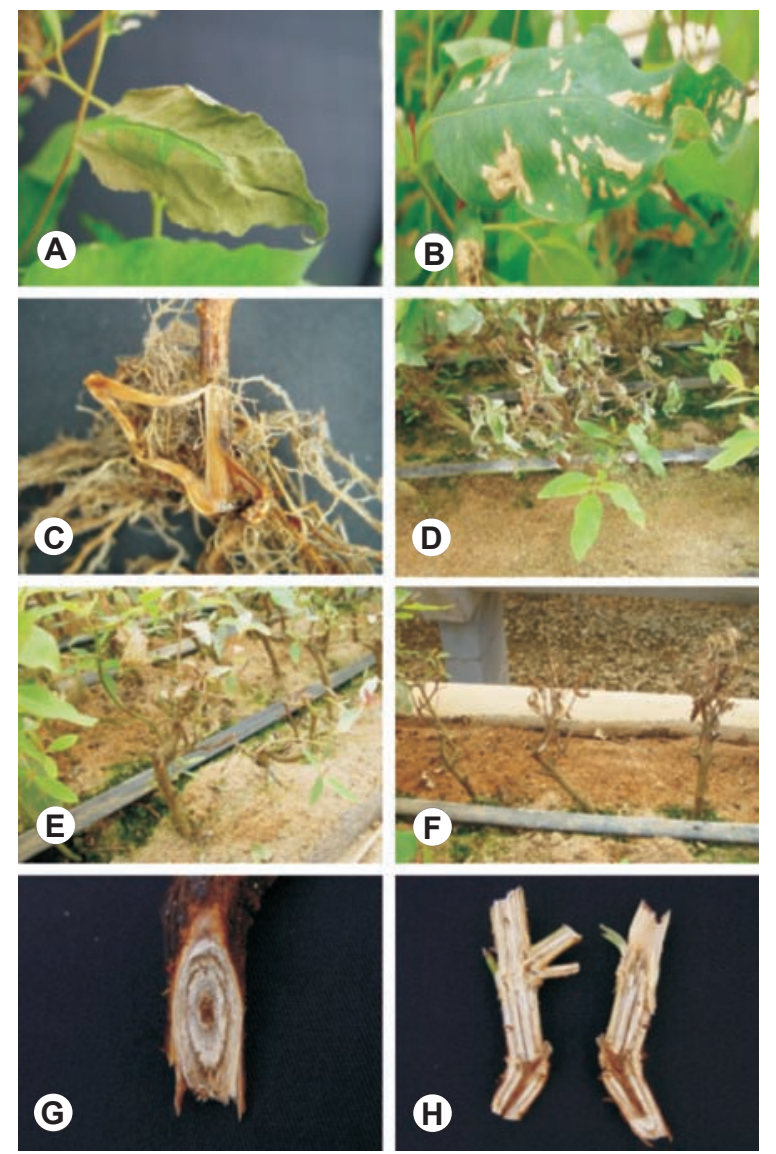

FIG. 1 - Sintomas da murcha bacteriana causada por Ralstonia solanacearum em minicepas clonais de eucalipto: A. Lesões foliares grandes e irregulares escuras; B. Lesões foliares de coloração marrom clara a palha dispersas no limbo foliar; C. Minicepa contendo sistema radicular malformado; D e E. Declínio de minicepas; F. Morte de minicepas com infecção bacteriana; G. Escurecimento anelar dos tecidos basais da minicepa; e H. Descoloração dos tecidos internos de minicepa. ao eixo principal, e ao longo de toda a haste principal da minicepa (Figura $1 \mathrm{H}$ ).

Estudos da ultra-estrutura de tecidos infectados revelaram perda da rigidez e desestruturação das paredes celulares dos tecidos vasculares e do parênquima (Figuras 2A e B), bem como intensa colonização e obstrução dos vasos do xilema pelo patógeno e pela massa de polissacarídeos extracelulares (Figuras 2C e D).

A infecção bacteriana em minicepas clonais ocasionou decréscimo na produção de miniestacas e nos índices de enraizamento. Além disso, miniestacas provenientes de minicepas doentes de vários clones, durante a fase de enraizamento, apresentaram sintomas de arroxeamento foliar sobre as nervuras (Figura 2E), necrose das hastes e morte (Figura 2F). Na fase de aclimatação a céu aberto, as folhas tornavam-se arroxeadas, seguindo-se a morte das plantas (Figura 2G), dependendo, provavelmente, da intensidade de colonização bacteriana. Em mudas prontas para expedição, com aproximadamente 100 dias de idade, os sintomas foram similares aos descritos para minicepas, com o surgimento de lesões foliares necróticas irregulares,

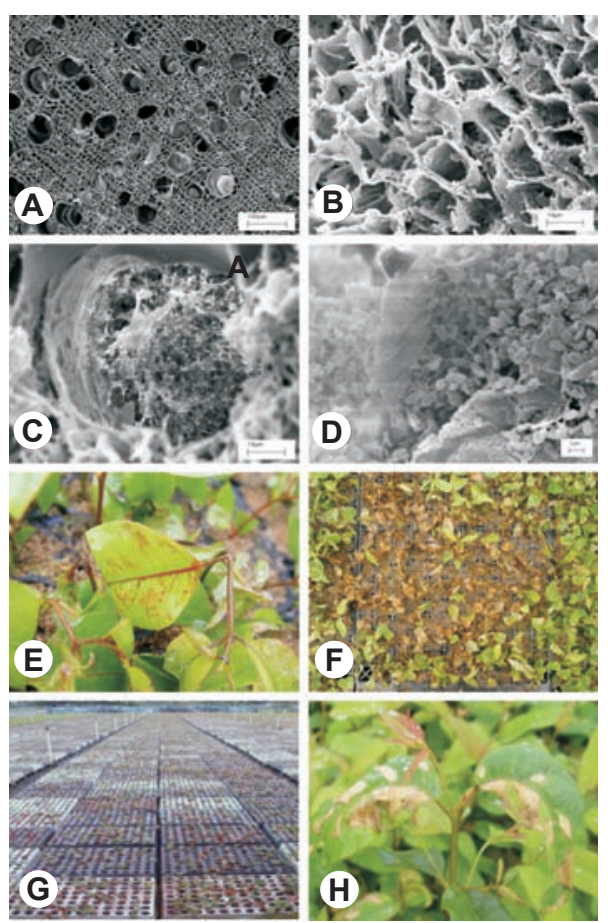

FIG. 2 - Sintomas da murcha bacteriana e colonização de Ralstonia solanacearum nos tecidos vasculares de minicepas clonais de eucalipto: A . Aspecto do tecido sadio; B. Desestruturação das paredes celulares de tecido infectado; $\mathbf{C}$. Colonização de um vaso do xilema; D. Detalhe da obstrução vascular causada pelo intenso crescimento bacteriano; E. Arroxeamento de nervuras foliares em miniestacas; F . Morte de miniestacas infectadas; G. Arroxeamento foliar e morte de mudas em fase de aclimatação a céu aberto; e H . Lesões foliares em mudas prontas para expedição. 
secas e dispersas no limbo foliar (Figura 2H). Nesta fase, sintomas mais severos de desfolha e morte das plantas também ocorreram.

\section{Descrição sintomatológica da doença no campo}

Ossintomas dadoençanocampo, em plantas oriundas de miniestacas infectadas, inicialmente, caracterizavamse por murcha e necrose na região da nervura central das folhas (Figura 3A), bronzeamento foliar e desfolha basal ascendente da planta (Figura 3B). Cortes perpendiculares do caule evidenciaram escurecimento do lenho a partir da região central (Figura 3C), de onde exsudava grande quantidade de pus bacteriano (Figura 3D). Geralmente, as árvores mais afetadas apresentavam problemas de malformação radicular (Figura 3E) e, ou, afogamento de coleto, o que dependendo da intensidade causava o subdesenvolvimento ou a morte das plantas, resultando em alta desuniformidade do plantio (Figura 3F).

\section{Diagnose da doença em viveiro e no campo}

$O$ teste de exsudação em tubo de ensaio permitiu constatar, de forma rápida, a presença de $R$. solanacearum em minicepas, com observação de exsudação de pus bacteriano a partir da base do tecido seccionado (Figura 3G). Todavia, por este teste, não foi possível observar exsudação da bactéria a partir de miniestacas ou de mudas infectadas ou de minicepas, aparentemente, com baixo índice de infecção. Por outro lado, pelo teste de exsudação em gota d'água (Figura $3 \mathrm{H}$ ), constatou-se, ao microscópio, a presença da bactéria, independentemente do tipo de material vegetal analisado. A ausência de sintomas nem sempre indicou sanidade do material vegetal.

Para plantas no campo, provavelmente em virtude da maior colonização dos tecidos pela bactéria, a observação macroscópica direta de exsudação de pus bacteriano sobre a superfície do tecido lenhoso foi suficiente para comprovar a infecção por $R$. solanacearum.

\section{Isolamento e testes de patogenicidade}

A partir das amostras de tecidos positivas no teste de exsudação, foram obtidos 46 isolados bacterianos originários dos Estados da Bahia (17), do Espírito Santo (13), do Maranhão (5), de Minas Gerais (10) e do Pará (1) (Tabela 1). Todos os isolados apresentaram colônias de aspecto fluido e coloração creme esbranquiçada quando cultivados em meio de Kado \& Heskett (1970), similares a $R$. solanacearum.

Dentre os isolados, 27 induziram reação de hipersensibilidade em folhas de fumo e colonizaram plantas de tomateiro e 30 isolados causaram necrose e morte em plantas de eucalipto. Houve correspondência entre reação de hipersensibilidade em fumo e patogenicidade em tomateiro e em eucalipto. Todavia, para os isolados UFV 17, UFV 56 e UFV 59, ocorreu resultado positivo somente para os testes de patogenicidade em eucalipto (Tabela 1).


FIG. 3 - Sintomas da murcha bacteriana em campo e testes diagnósticos: A. Murcha e necrose de nervuras; B. Desfolha basal ascendente; C. Escurecimento do lenho causado pela infecção; D. Exsudação de pus bacteriano; E. Enovelamento radicular e sintomas de escurecimento causado pela colonização bacteriana; F. Falta de uniformidade no crescimento e mortalidade de plantas no campo; G. Exsudação de pus bacteriano em teste diagnóstico em tubo de ensaio contendoágua; $\mathbf{H}$.Exsudação bacterianaem gota d'água.

\section{Deteç̧ão por PCR}

Com o par de oligonucleotídeos PS1/PS2, a partir das colônias dos isolados considerados patogênicos e dos isolados padrões de $R$. solanacearum (CNPH 174, CNPH 211 e CNPH 221), foi possível amplificar um fragmento de aproximadamente $500 \mathrm{pb}$. A natureza do produto amplificado foi confirmada após análise de restrição com a enzima TaqI (Figura 4). Em três casos, houve amplificação para os isolados (UFV 19, UFV 45 e UFV 47) negativos para os testes de patogenicidade em eucalipto e em dois, não ocorreu amplificação para os isolados (UFV 56 e UFV 59) patogênicos ao eucalipto. Em relação à patogenicidade ao tomateiro, a PCR foi positiva para dois isolados (UFV 45 e UFV 47) considerados não patogênicos. Houve amplificação para três isolados negativos (UFV 19, UFV 45 e UFV 47) 
TABELA 1 - Reação de hipersensibilidade (HR) em fumo, patogenicidade ao tomateiro e ao eucalipto, detecção por PCR e biovar dos isolados bacterianos obtidos de eucalipto

\begin{tabular}{|c|c|c|c|c|c|c|c|}
\hline \multirow[b]{2}{*}{ Isolado } & \multirow[b]{2}{*}{ Origem } & \multirow[b]{2}{*}{ Hospedeiro } & \multirow[b]{2}{*}{ HR } & \multicolumn{2}{|c|}{ Patogenicidade } & \multirow[b]{2}{*}{ PCR } & \multirow[b]{2}{*}{ Biovar } \\
\hline & & & & Tomateiro & Eucalipto & & \\
\hline UFV 1 & Espírito Santo & Eucalyptus sp. & - & ND* & - & - & 1 \\
\hline UFV 2 & Espírito Santo & Eucalyptus sp. & - & ND & - & - & 1 \\
\hline UFV 3 & Bahia & Eucalyptus sp. & - & ND & - & - & 1 \\
\hline UFV 4 & Bahia & Eucalyptus sp. & + & + & + & + & 1 \\
\hline UFV 5 & Bahia & Eucalyptus sp. & - & ND & - & - & 1 \\
\hline UFV 7 & Bahia & Corymbia citriodora & + & + & + & + & 1 \\
\hline UFV 8 & Bahia & Corymbia citriodora & + & + & + & + & 1 \\
\hline UFV 9 & Maranhão & Eucalyptus sp. & + & + & + & + & 1 \\
\hline UFV 10 & Maranhão & Eucalyptus sp. & + & + & + & + & 1 \\
\hline UFV 11 & Espírito Santo & Eucalyptus sp. & - & ND & - & - & 1 \\
\hline UFV 12 & Maranhão & Eucalyptus sp. & + & + & + & + & 1 \\
\hline UFV 13 & Minas Gerais & Eucalyptus sp. & + & + & + & + & 1 \\
\hline UFV 14 & Minas Gerais & Eucalyptus sp. & + & + & + & + & 1 \\
\hline UFV 15 & Minas Gerais & Eucalyptus sp. & + & + & + & + & 1 \\
\hline UFV 17 & Espírito Santo & Eucalyptus sp. & - & - & + & + & 1 \\
\hline UFV 18 & Espírito Santo & Eucalyptus sp. & + & + & + & + & 1 \\
\hline UFV 19 & Espírito Santo & Eucalyptus sp. & - & ND & - & + & 1 \\
\hline UFV 20 & Espíri to Santo & Eucalyptus sp. & + & + & + & + & 1 \\
\hline UFV 21 & Espírito Santo & Eucalyptus sp. & - & ND & - & - & 1 \\
\hline UFV 22 & Espírito Santo & Eucalyptus sp. & - & ND & - & - & 1 \\
\hline UFV 26 & Espírito Santo & Eucalyptus sp. & + & + & + & + & ND \\
\hline UFV 27 & Bahia & Corymbia citriodora & + & + & + & + & 1 \\
\hline UFV 28 & Maranhão & Eucalyptus sp. & - & ND & - & - & 1 \\
\hline UFV 29 & Maranhão & Eucalyptus sp. & - & ND & - & - & 1 \\
\hline UFV 30 & Minas Gerais & Eucalyptus sp. & + & + & + & + & 1 \\
\hline UFV 31 & Minas Gerais & Eucalyptus sp. & + & + & + & + & 1 \\
\hline UFV 32 & Bahia & Eucalyptus sp. & + & + & + & + & 1 \\
\hline UFV 34 & Pará & Eucalyptus sp. & + & + & + & + & 1 \\
\hline UFV 35 & Bahia & Eucalyptus sp. & - & ND & - & - & 1 \\
\hline UFV 36 & Bahia & Eucalyptus sp. & - & ND & - & - & 1 \\
\hline UFV 37 & Bahia & Eucalyptus sp. & - & ND & - & - & 1 \\
\hline UFV 38 & Bahia & Eucalyptus sp. & + & + & + & + & 1 \\
\hline UFV 39 & Espírito Santo & Eucalyptus sp. & - & ND & - & - & 1 \\
\hline UFV 41 & Espírito Santo & Eucalyptus sp. & - & ND & - & - & 1 \\
\hline UFV 45 & Minas Gerais & Eucalyptus sp. & - & - & - & + & 1 \\
\hline UFV 47 & Bahia & Eucalyptus sp. & - & - & - & + & ND \\
\hline UFV 48 & Bahia & Eucalyptus sp. & + & + & + & + & ND \\
\hline UFV 49 & Espírito Santo & Eucalyptus sp. & + & + & + & + & 1 \\
\hline UFV 51 & Minas Gerais & Eucalyptus sp. & + & + & + & + & 1 \\
\hline UFV 52 & Minas Gerais & Eucalyptus sp. & + & + & + & + & 1 \\
\hline UFV 53 & Minas Gerais & Eucalyptus sp. & + & + & + & + & 1 \\
\hline UFV 54 & Bahia & Eucalyptus sp. & - & ND & - & - & 1 \\
\hline UFV 55 & Bahia & Eucalyptus sp. & + & + & + & + & 1 \\
\hline UFV 56 & Bahia & Eucalyptus sp. & - & ND & + & - & 1 \\
\hline UFV 58 & Bahia & Eucalyptus sp. & - & ND & - & - & 1 \\
\hline UFV 59 & Minas Gerais & Eucalyptus sp. & - & ND & + & - & 1 \\
\hline CNPH 174 & Distrito Federal & Solanum tuberosum L. & + & + & + & + & 2 \\
\hline CNPH 211 & Goiás & L. esculentum Mill. & + & + & + & + & 3 \\
\hline CNPH 221 & Distrito Federal & L. esculentum & + & + & + & + & 1 \\
\hline
\end{tabular}

*Não determinado.

quanto aos testes de HR (Tabela 1). Nas condições de PCR utilizadas, nenhum produto foi amplificado de colônias de outras bactérias patogênicas ou rizobactérias, associadas a eucalipto, pertencentes aos gêneros Xanthomonas, Pseudomonas, Rhizobium, Erwinia e Bacillus.

\section{Quantificação das perdas causadas pela doença}

A murcha bacteriana, distribuída nos Estados da Bahia, do Espírito Santo, do Maranhão, de Minas Gerais e do Pará afetou 28 clones de eucalipto e resultou no descarte e destruição de 553.991 minicepas, 6.837.691 


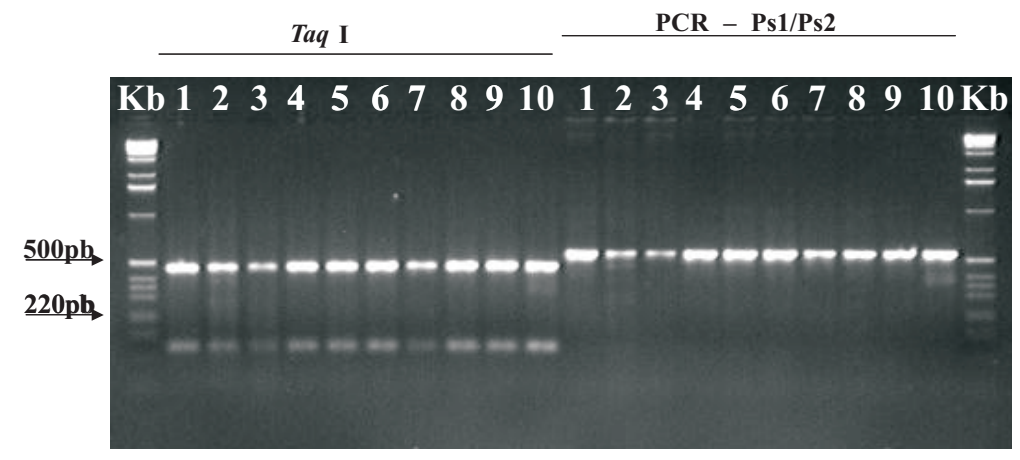

FIG. 4 - PCR-RFLP para detecção de Ralstonia solanacearum. Amplificação realizada a partir de colônias isoladas sem extração de DNA utilizando os oligonucleotídeos PS1 (5' - AGTCGAACGGCAGCGGGGG - 3') e PS2 (5' - GGGGATTTCACATCGGTCTTGCA - 3') e clivagem com enzima TaqI. À direita, observa-se o produto da PCR realizada a partir de colônias de 10 isolados e à esquerda, a clivagem do produto da $\mathrm{PCR}$. Kb - Marcador molecular de comprimento (1Kb DNA Ladder); linha 1 - Controle positivo com isolado CNPH 174; linha 2 - Isolado obtido de Eucalyptus spp. da Bahia (RS 38); linhas 3 e 4 isolados originários de Eucalyptus spp. de Minas Gerais (RS 30 e RS 31); linhas 5, 6 e 7 isolados obtidos de Eucalyptus spp. do Espírito Santo (RS 49, RS 20 e RS 18); linhas 8, 9 e 10 isolados oriundos de Eucalyptus spp. do Maranhão (RS 12, RS 10 e RS 9).

propágulos vegetativos e de 11.266 .819 mudas prontas para expedição (Tabela 2). Os prejuízos econômicos totalizaram aproximadamente R\$ 6.000.000,00 (US\$ 2.764.977,00), considerando somente o descarte de material vegetal.

\section{DISCUSSÃO}

O presente trabalho constitui um relato das características e da importância da murcha bacteriana para viveiros clonais de eucalipto. Analogamente ao que ocorre em outros hospedeiros (Vasse et al., 1995), os sintomas macroscópicos observados e as análises ultraestruturais dos tecidos infectados indicam que, em minicepas doentes, a obstrução dos vasos pelo material capsular e a perda de capilaridade vascular resultante da degradação enzimática dos vasos do xilema, reduzem a translocação de água ocasionando os sintomas de murcha e morte da planta. A natureza lenhosa do eucalipto pode determinar a baixa freqüência de murcha, que geralmente ocorre em minicepas com sistema radicular afetado. Várias espécies florestais são hospedeiras de R. solanacearum. Entretanto, relatos sobre o declínio de árvores são limitados. Embora os sintomas típicos variem com a espécie hospedeira, em geral, plantas arbóreas infectadas por $R$. solanacearum apresentam sintomas de murcha permanente, descoloração interna do lenho e obstrução vascular por massas de células bacterianas e material capsular (Supriadi et al., 2001).

A detecção da bactéria em minicepas e mudas assintomáticas sugere que a doença apresenta desenvolvimento lento e que, sob determinadas condições ambientais e de predisposição do hospedeiro, há um aumento de colonização dos tecidos e expressão dos sintomas. No sistema atual de produção de mudas clonais de eucalipto, a coleta intensiva de brotações para estaquia e a realização de podas drásticas em minicepas induzem a morte de raízes o que resulta na debilitação fisiológica das plantas, tornando-as mais vulneráveis à infecção. Além disso, a freqüentes fertirrigações e a temperatura elevada do leito de areia dos canteiros favorecem a multiplicação e disseminação do patógeno em minijardim clonal.

Em eucalipto, existem diferenças entre os sintomas da doença em minicepas e plantas no campo. As minicepas infectadas em relação às sadias apresentam menor turgescência dos tecidos foliares, mas raramente atingem ponto de murcha permanente, desfolha e necrose foliar no formato de "V" invertido, como observado no campo em plantas jovens mais suscetíveis (Ferreira \& Milani, 2002). A severidade da doença varia de acordo com as condições ambientais. Na península de Leizhou (Guangdong), a murcha bacteriana do eucalipto ocorre anualmente de abril a novembro, sendo mais severa de julho a agosto, período mais quente e úmido (Liang et al., 1992). Sob condições naturais de infecção, os sintomas surgem no campo em plantas com 3-4 meses após o plantio e a enfermidade pode ser aguda ou crônica. No primeiro caso, a doença progride rapidamente podendo causar a morte de árvores jovens em 2-3 semanas após o surgimento dos primeiros sintomas. As folhas das árvores infectadas murcham e entram em colapso rapidamente, os vasos do xilema tornam-se escurecidos e na superfície dos ramos e haste doentes surgem estrias marrons a marrons escuras. As raízes tornam-se necróticas e a partir da superfície de cortes em hastes e raízes, nota-se exsudação de pus bacteriano. No tipo crônico, a doença progride mais lentamente e as árvores infectadas têm crescimento reduzido, as folhas tornam-se de coloração avermelhada e, finalmente, murcham, culminado com a morte da planta após 2 a 6 
TABELA 2 - Clones afetados, perdas de minicepas, propágulos vegetativos e de mudas clonais de eucalipto em conseqüência da incidência de Ralstonia solanacearum em diferentes regiões do Brasil.

\begin{tabular}{|c|c|c|c|c|c|}
\hline \multirow[b]{2}{*}{ Viveiro } & \multirow[b]{2}{*}{ Local } & \multirow{2}{*}{$\begin{array}{c}\text { Clones } \\
\text { afetados }\end{array}$} & \multicolumn{3}{|c|}{ Material vegetal } \\
\hline & & & $\begin{array}{c}\text { Cepas/ } \\
\text { Minicepas }\end{array}$ & Propágulos & Mudas \\
\hline 01 & Bahia & 14 & 29.311 & - & 625.000 \\
\hline 02 & Espírito Santo & 07 & 305.000 & 6.156 .000 & 7.344 .000 \\
\hline 03 & Ma ranhão & 01 & 58.000 & - & - \\
\hline 04 & Minas Gerais & 03 & 62.000 & 262.719 & 1.176 .796 \\
\hline 05 & Minas Gerais & 02 & 99.680 & 376.336 & 2.047 .896 \\
\hline \multirow[t]{2}{*}{06} & Pará & 01 & & 42.636 & 73.127 \\
\hline & Total & 28 & 553.991 & 6.837 .691 & 11.266 .819 \\
\hline
\end{tabular}

meses (Supriadi et al., 2001). Observou-se ainda que em alguns casos havia infecção simultânea de $R$. solanacearum e Ceratocystis fimbriata Ellis \& Halst.

Embora não tenha sido objeto principal do estudo, é importante considerar as possíveis fontes de inóculo da bactéria em viveiros, com vistas à adoção de medidas de controle. Acredita-se que o material propagativo (macroestacas) originário de matrizes infectadas no campo seja a principal fonte de inóculo primário de $R$. solanacearum em viveiros. Desta forma, é fundamental estabelecer o minijardim com mudas comprovadamente sadias. Potencialmente, existem outras fontes de contaminação como a água de irrigação e a areia utilizada no leito dos canaletões, pois esta bactéria, endêmica em diferentes regiões tropicais e subtropicais do mundo (Hayward, 1991) e distribuída no território nacional (Robbs et al., 1988), é capaz de, na ausência do hospedeiro, sobreviver no solo por períodos prolongados, associada com a matéria orgânica ou com plantas daninhas, sem induzir sintomas (Hayward, 1991). Pode também entrar em estado de dormência, permanecendo como células viáveis, mas não cultiváveis (Grey \& Steck, 2001). Assim como empregado para erradicação de outros microrganismos fitopatogênicos (Alfenas et al., 2004), tesouras de poda e recipientes reutilizados no viveiro devem ser desinfestados em água quente a $80^{\circ} \mathrm{C} / 1$ min para evitar a possível disseminação de $R$. solanacearum.

Considerando as possíveis fontes de inóculo para minijardins clonais de eucalipto, torna-se necessário dispor de técnicas confiáveis e de alta sensibilidade para deteç̧ão de $R$. solanacearum, para realização do controle preventivo. Existem várias técnicas para detecção do patógeno em material vegetal e em solo. A técnica mais comum, mas menos sensível, consiste na transferência de suspensão de solo para meios de cultura seletivos. A bactéria em meio de cultivo apresenta, geralmente, colônia esbranquiçada e fluída, com 3-5 cm de diâmetro após 2-3 dias de incubação a $29^{\circ} \mathrm{C}$. A sensibilidade desse método permite detectar até $100 \mathrm{ufc} / \mathrm{g}$ solo (Pradhanang et al., 2000). Todavia, esse método requer treinamento para distinguir colônias típicas do patógeno de bactérias saprófitas, o que limita o seu uso em larga escala. Além disso, a sensibilidade do método varia entre amostras de solo, dependendo, por exemplo, de outros microrganismos que podem inibir o crescimento da bactéria. O uso de plantas indicadoras, como o tomateiro (Graham \& Lloyd, 1978), também apresenta baixa sensibilidade $\left(10^{4}\right.$ a $10^{5}$ cél./g de solo) como fator limitante. O ELISA (Enzyme-Linked Immuno-Sorbent Assay) indireto apresenta sensibilidade $\left(10^{4}\right.$ cél./g de solo) e especificidade baixas (Priou et al., 1998). Todavia, a sensibilidade pode ser aumentada pela incubação prévia dos extratos de solo em caldos nutritivos seletivos para multiplicação da bactéria alvo (Priou et al., 1998). Outras variações do ELISA consistem nas técnicas NCMELISA (Nitrocellulose Membrane - ELISA) e DAS-ELISA (Double Antibody Sandwich Immunoassay) (Priou et al., 1998). Na União Européia, o método padrão para monitorar a ocorrência de $R$. solanacearum em batata-semente envolve o uso da técnica IFAS (Indirect Immunofluorescence Antibody Staining) e isolamento em meio seletivo. Os resultados positivos determinados pela técnica IFAS são confirmados por bioensaio com plantas de tomate (indicadoras) e pela detecção de seqüências de DNA específicas por PCR a partir da cultura pura da bactéria isolada em meio seletivo de cultura (OEPP/EPPO, 2004). Testes diagnósticos utilizando PCR a partir de amostras de água, sementes, solo e de material vegetal têm mostrado rapidez e especificidade de detecção (Seal et al., 1999; Lee \& Wang, 2000; Poussier et al., 2002).

Em diversas culturas, é difícil o emprego de plantas resistentes para o controle da doença em face à alta variabilidade na população do patógeno e pela instabilidade da resistência em função das condições de temperatura e umidade do solo (Mew \& Ho, 1977). Todavia, em condições de campo, Wu \& Liang (1988b) observaram variações no nível de resistência para certas procedências, sendo que $E$. grandis x E. urophylla, E. saligna, Corymbia citriodora e E. exserta F. Muell. foram mais resistentes à murchabacteriana. Dianese \& Dristig (1993) concluíram, por meio de inoculações artificiais, que isolados de $R$. solanacearum 
oriundos de eucalipto foram patogênicos a $E$. deglupta Blume, E. microcorys F. Muell., E. pilularis Sm, E. punctata D.C., E. pyrocarpa L. Johnson \& D. Blaxell, E. robusta Sm., E. saligna e E. urophylla. As espécies E. camaldulensis, $C$. citriodora, E.cloeziana F. Muell, E. deanei Maiden, E.pellita, E. grandis, E. resinifera Sm., E. tereticornis e C. torelliana F. Muell. foram consideradas resistentes. $\mathrm{Na} C h i n a, \mathrm{Li} \& \mathrm{Wu}$ (1996) observaram que espécies de crescimento rápido como E. urophylla, E. grandis, E. saligna e os híbridos E. grandis $\mathrm{x}$ E. urophylla ou E. urophylla $\mathrm{x}$ E. grandis, com menos de dois anos, são altamente suscetíveis. As diferenças quanto ao nível de resistência para uma mesma espécie podem estar relacionadas com o uso de procedências distintas, o que deve ser mais bem investigado.

O controle biológico tem despontado como alternativa promissora. Para a cultura do eucalipto, o tratamento de mudas com isolados da rizobactéria Pseudomonas fluorescens indicam o seu potencial no controle da murcha do eucalipto na China (Ran et al., 2005). Atualmente, o produto Rizolyptus ${ }^{\circledR}$ à base de rizobactérias, efetivo para o controle de algumas doenças em viveiro (Alfenas et al., 2004), está sendo testado para o controle de $R$. solanacearum em minijardim clonal de Eucalyptus spp.

\section{AGRADECIMENTOS}

Ao Dr. Carlos A. Lopes, EMBRAPA - Hortaliças (CNPH), Brasília, DF, pela revisão do texto e pelas culturas típicas de Ralstonia solanacearum cedidas, ao estudante de Engenharia Florestal (UFV) Rafael Ferreira Alfenas pela ajuda nas análises de exsudação de pus bacteriano e à Aracruz Celulose, CAF Florestal, Jari Celulose, Plantar e Ferro Gusa pelo apoio na realização dos trabalhos.

\section{REFERÊNCIAS BIBLIOGRÁFICAS}

ALFENAS, A.C. Potential and present status of Eucalyptus and Acacia mangium diseases in Northern Sumatra. Consultancy Report to P.T. Inti Indorayon Utama Company, Indonesia. DFP/ UFV, 53p. (Relatório Técnico-Científico). 1993.

ALFENAS, A.C., ZAUZA, E.A,V., MAFIA, R.G. \& ASSIS, T.F. Clonagem e doenças do eucalipto. Viçosa, MG. Editora UFV. 2004. 442p.

ASKIEW, E. \& TEVOROW, P.R. Management of bacterial wilt of tobacco. In: Hayward, A.C. \& Hartman, G.L. (Eds.). Bacterial wilt: the disease and its causative agent, Pseudomonomas solanacearum. Wallingford. UK. CAB International. 1994. pp.179-198.

BRINGEL, J.M.M., TAKATSU, A. \& UESUGI, C.H. Colonização radicular de plantas cultivadas por Ralstonia solanacearum, biovares 1, 2 e 3. Scientia Agricola 58:497-500. 2001.

CIESLA, W.M., DIEKMANN, M. \& PUTTER, C.A. Eucalyptus spp. FAO/IPGRI. Technical Guide-lines for the safe movement of germplasm, no 17. Rome, Italy: FAO/IPGRI. 1996.

COUTINHO, T.A., ROUX, J., RIEDEL, K.H., TERBLANCHE, J. \& WINGFIELD, M.J. First report of bacterial wilt caused by
Ralstonia solanacearum on eucalypts in South Africa. Forest Pathology 30:205-210. 2000.

DIANESE, J.C. \& DRISTIG, M.C.G. Screening Eucalyptus selections for resistance to bacterial wilt caused by Pseudomonas solanacearum. In: Hartman, G.L. \& Hayward, A.C. (Eds.) Bacterial Wilt Proceedings of an International Conference, Kaohsiung, Taiwan. 1992. pp. 206-210. 1993.

DIANESE, J.C. \& TAKATSU, A. Pseudomonas solanacearum biovar 1 isolada de eucalipto em Monte Dourado, Estado do Pará. Fitopatologia Brasileira 10:362. 1985. (Resumo)

FERREIRA, F.A. \& MILANI, D. Diagnose visual e controle das doenças abióticas e bióticas do eucalipto no Brasil. International Paper. 2002.

GRAHAM, J. \& LLOYD, A.B. An improved indicator plant method for the detection of Pseudomonas solanacearum race 3 in soil. Plant Disease Reporter 62:35-37. 1978.

GREY, B.E. \& STECK, T.R. The viable but nonculturable state of Ralstonia solanacearum may be involved in long-term survival and plant infection. Applied and Environmental Microbiology 67:3866-3872. 2001.

HAYWARD, A.C. Biology and epidemiology of bacterial wilt caused by Pseudomonas solanacearum. Annual Review of Phytopathology 29:65-87. 1991.

KADO, E.I. \& HESKETT, M.G. Selective media for isolation of Agrobacterium, Corynebacterium, Erwinia, Pseudomonas and Xanthomonas. Phytopathology 60:969-976. 1970.

KELMAN, A. The relationship of pathogenicity in Pseudomonas solanacearum to colony appearance on a tetrazolium medium. Phytopathology 44:693-695. 1954.

LEE, YUNG-AN \& WANG, CHI-CHUNG. The design of specific primers for the detection of Ralstonia solanacearum in soil samples by polymerase chain reaction. Botanical Bulletin of Academia Sinica 41:121-128. 2000.

LI, H. \& WU, X.Y. The current status, causes and control of forest diseases in Haiman province. Tropical Forestry 24:101-103. 1996.

LIANG, Z.C., GUO, Q. \& WU, Q.P. Bacterial wilt of eucalyptus in South China. Bacterial Wilt Newsletter 8:5. 1992.

MEW, T.W. \& HO, W.C. Effect of soil temperature on resistance of tomato cultivars to bacterial wilt. Phytopathology 67:909-911. 1977.

OEPP/EPPO (Organisation Européenne pour la Protection des Plantes/European Plant Protection Organisation). Ralstonia solanacearum. Diagnostic protocols for regulated pests. OEPP/ EPPO Bulletin 34:173-178. 2004.

PASTRIK, K.H. \& MAISS, E. Detection of Ralstonia solanacearum in potato tubers by polymerase chain reaction. Journal of Phytopathology 148:619-626. 2000.

POUSSIER, S., CHÉRON, J.J., COUTEAU, A. \& LUISETTI, J. Evaluation of procedures for reliable PCR detection of Ralstonia solanacearum in common natural substrates. Journal of Microbiological Methods 51:349-359. 2002.

PRADHANANG, P.M., ELPHINSTONE, J.G. \& FOX, R.T.V. Sensitive detection of Ralstonia solanacearum in soil: a comparison of different detection detection techniques. Plant Pathology 49:414422. 2000. 
PRIOU, S. GUTARRA, L., FERNANDES, H. \& ALEY, P. Sensitive detection of Ralstonia solanacearum in latently infected potato tubers and soil by post enrichment ELISA. CIP Program Report. p.111-122. 1998.

RAN, L.S., LIU, C.Y., WU, G.J., VAN LOON, L.C. \& BAKKER, P.A.H.M. Suppression of bacterial wilt in Eucalytpus urophylla by fluorescent Pseudomonas spp. in China. Biological Control 32:111-120. 2005.

ROBBS, C.F., CRUZ, A.P. \& NETO, J.R. Algumas estratégias de controle à murcha bacteriana (Pseudomonas solanacearum) em eucaliptos. EMBRAPA Jaguariúna, SP. Comunicado Técnico, nº 3. 4p. 1988.

SEAL, S.E., TAGHAVI, M., FEGAN, N., HAYWARD, A.C. \& FEGAN, M. Determination of Ralstonia (Pseudomonas) solanacearum rDNA subgroups by PCR tests. Plant Pathology 48:115-120. 1999.

SUDO, S., OLIVEIRA, G.H.N. \& PEREIRA, A.C. Eucalipto (Eucalyptus sp.) e bracatinga (Mimosa scabrella Penth), novos hospedeiros de Pseudomonas solanacearum E.F. Smith. Fitopatologia Brasileira 8:631. 1983. (Resumo)

SUPRIADI, KARDEN, M. \& SITEPU, D. Bacterial wilt disease of woody trees caused by Pseudomonas solanacearum: a review. Jurnal Litbang Pertanian local 20:106-112. 2001.

VASSE, J., FREY, P. \& TRIGALET, A. Microscopic studies of intercellular infection and protoxylem invasion of tomato roots by Pseudomonas solanacearum. Molecular Plant-Microbe Interaction 8:241-251. 1995.

WANG, W.Y. Survey of Eucalyptus disease in Taiwan. Bulletin Taiwan Forest Research Institute 7:179-194. 1992.

WU, Q.P. \& LIANG, Z.C. Identification and pathogenic tests of the causal organism of the bacterial wilt of Eucalyptus. Journal South China Agriculture University 9:59-67. 1988a.

WU, Q.P. \& LIANG, Z.C. Selection of species and provenance of Eucalyptus for resistance to bacterial wilt. Journal South China Agriculture University 9:41-45. 1988b.

YABUUCHI, E., KOSAKO, Y., YANO, I., HOTTA, H. \& NISHIUCHI, Y. Transfer of two Burkholderia and an Alcaligenes species to Ralstonia gen. nov.: proposal of Ralstonia pickettii (Ralston, Palleroni and Douderoff 1973) comb. nov., Ralstonia solanacearum (Smith 1896) comb. nov. \& Ralstonia eutropha (Davis 1969) comb. nov. Microbiology and Immunology 39:897904. 1995. 